\title{
REFLEXIONES SOBRE LA AUTONOMIA O SUFICIENCIA FINANCIERA DE LAS CORPORACIONES LOCALES SEGUN LA CONSTITUCION ESPAÑOLA
}

\author{
por \\ Manuel González Sánchez \\ Profesor Titular de Derecho Financiero y Tributario \\ de la Universidad de Salamanca
}

SUMARIO: I. PLANTEAMIENTO GENERAL.-II. AUTONOMIA O SUFICIENCIA FINANCIERA DE LAS CORPORACIONES LOCALES.-III. NATURALEZA Y CARACTERISTICAS DE LA AUTONOMIA FINANCIERA DE LAS CORPORACIONES LOCALES.-IV. SIGNIFICADO QUE PUEDE ATRIBUIRSE A LOS RECURSOS DE LAS CORPORACIONES LOCALES QUE NO ESTAN COMPRENDIDOS ENTRE LOS QUE LA CONSTITUCION CALIFICA DE FUNDAMENTALES.-V. COMO DEBE SUBSANARSE CUALQUIER ALTERACION EN LOS RECURSOS FUNDAMENTALES POR PARTE DEL ESTADO Y DE LAS COMUNIDADES AUTONOMAS.

\section{PLANTEAMIENTO GENERAL}

Con la aparición en nuestra organización territorial' de las Comunidades Autónomas, el tema de la actividad financiera de los Entes locales resulta más complicado. 
Según el artículo 137 de la Constitución Española: «El Estado se organiza territorialmente en Municipios, en Provincias y en las Comunidades Autónomas que se constituyan. Todas estas Entidades gozan de autonomía para la gestión de sus respectivos intereses» (1).

La autonomía jurídico-institucional parece resuelta en la Constitución en los artículos 140 y siguientes para los Entes locales, y en los artículos 143 y siguientes para las Comunidades Autónomas.

Aquí nos vamos a ocupar de un aspecto del ámbito juridico-constitucional de las Corporaciones locales, me refiero concretamente al fenómeno jurídico-financiero de las Corporaciones locales (2).

Ante la diferente redacción de los artículos 142 (para las Corporaciones locales) y 156, 157 y 158 (para las Comunidades Autónomas), la doctrina se ha planteado el problema del significado de estos artículos.

Quizá el tema se ha planteado más bajo la perspectiva de las Comunidades Autónomas que respecto de las Corporaciones locales.

Por ello consideramos de interés tratar el contenido y el alcance que puede atribuirse al artículo 142 de la Constitución, precepto sencillo y claro, pero de gran significado técnico (3).

(1) Sobre esta materia puede verse la Sentencia del Tribunal Constitucional de 2 de febrero de 1981: ponente. Rafael Gomez-Ferrer Morant (suplemento al Boletin Oficial del Estado de 24 de febrero de 1981, num. 47). Recurso de inconstitucionalidad numero 186/1980. En esta Sentencia se dice: "De aqui que el articulo 137 de la Constitucion delimite el ambito de estos poderes autonomos, circunscribiendolos a la "gestion de sus respectivos intereses", lo que exige que se dote a cada Ente de todas las competencias propias y exclusivas que sean necesarias para satisfacer el interes respectivo". De acuerdo. pues. con la Constitucion. la autonomia que garantiza para cada Entidad lo es en función del criterio del respectivo interes: interés del Municipio, de la Provincia. de la Comunidad Autonoma.

(2) G. Solé Villalonga: "El orden constitucional y el sistema fiscal", en Constitución y Economia, Madrid. Centro de Estudios de Comunicación Economica, S. A.. 1978. pág. 126. advierte de la trayectoria de la insuficiencia de medios, al decir: "Las Corporaciones locales vienen aquejadas en España, tradicionalmente, de una financiacion muy escasa. $\mathrm{Y}$ al decir muy escasa no me refiero a cifras absolutas, sino comparativas".

(3) El significado de este precepto puede apreciarse a la luz de la evolución historica en nuestro pais y mediante un analisis del Derecho comparado.

En relación con-los antecedentes historicos se puede observar que no existe algo semejante al articulo 142 de nuestra Constitucion, pues o bien se acude a los arbitrios con caracter secundario, como sucede en la Constitución de 1812 (articulo 322), o bien se preve la suficiencia de medios garantizada por el Estado mediante Ley, como en el Pro'ecto de Constitucion Federal de la Republica Española de 1873 (articulo 108). en el Anitproyecto de la Constitucion de la Monarquia Española de 1929 (art. 92, 6.a) y en la Ley Organica del Estado de I de enero de 1967 (art. 47) o, finalmente, preocupa mas la coordinación entre la Hacienda estatal y la local, asi en la Constitucion de 1869 (articulo 99.5..$^{\circ}$ y en la Constitución de la Monarquia de 1876 (art. 84). La Constitución de la Republica Española de 9 de diciembre de 1931, en su articulo 9.. se limita a determinar la autonomia de los Entes locales.

Por lo qu? se refiere al Derecho comparado tampoco existen preceptos iguales al 


\title{
II. AUTONOMIA O SUFICIENCIA FINANCIERA DE LAS CORPORACIONES LOCALES
}

\author{
Algún autor, como consecuencia de que la autonomía financiera
} parece corresponder mejor, según la terminologia constitucional, a las Comunidades Autónomas, prefiere reservar para las Corporaciones locales lo que denomina «suficiencia financiera» (4).

nuestro. aunque existen algunos con cierta semejanza. La Constitución de México de 1917 presenta cierta semejanza con el articulo 142 de nuestra Constitúción. en cuanto que prevé que los Municipios administraran libremente su hacienda. que estara formada por las contribuciones suficientes para atender las necesidades municipales y se estableceran por Ley. En la Constitucion de la Republica Portuguesa de 2 de abril de 1976. tambien se preve la autonomia de las Entidades locales con patrimonio y hacienda propios. que sera establecida por Ley: pero los ingresos propios se refieren mas a los ingresos patrimoniales y a las tasas. La Constitución de la Republica Francesa de 4 de octubre de 1958 dispone en su articulo 34 que la Ley determina los principios fundamentales "... de la libre administracion de las colectividades locales. de sus competencias y de sus recursos". La Constitución de la Republica Italiana de 27 de diciembre de 1947. en el articulo 119. regula la coordinación por Ley entre la Hacienda del Estado. de las Regiones. de las Provincias y de los Municipios. y en el articulo 128 se dispone que las Provincias y los Municipios son autonomos. segun la Ley. En la Ley Fundamental de Bonn de 23 de mayo de 1949. se preven ayudas para inversiones a los Municipios (art. 104. a), 4| y la compensación en caso de aumento de gastos o reducción de ingresos (art. 106, 8), pero los ingresos y los gastos de los Municipios son ingresos y gastos de los Estados (art. 106.9). y tambien se preven impuestos que son asignados y corresponden a los Municipios (art. 108.4.5.6 y 7). En las Constituciones de los paises socialistas se pueden distinguir tres perspectivas o niveles: a) Constituciones que permiten a los Entes locales una gestion autonomica de sus propios medios financieros, asi el articulo $43.1 . c)$, de la Constitucion de Hungria de 20 de agosto de 1949, texto único de 19 de abril de 1972. y la Constitución de la Republica Democrática Alemana de 6 de abril de 1968. version aprobada por !a Ley de Decisiones y Enmiendas a la Constitución de 7 de octubre de 1974. b) Autonomia financiera de los Entes locales condicionada a lo dispuesto en Ley ordinaria. asi los articulos 94 y 95 de la Constitución del Vietnam de 1 de enero de 1960, proclamada vigente en la Republica Socialista del Vietnam en la primera sesion de la Asamblea Nacional Vietnamita, celebrada el 2 de julio de 1976. c) Se permite a los Entes locales aprobar sus presupuestos y el plan economico y reciben los medios del Estado. en este sentido, las Constituciones de Rumania de 20 de agosto de 1965 , texto unico de 27 de diciembre de 1974 (art. 87); de Bulgaria de 16 de mayo de 1971 (art 114); de la República Democratica Popular de Corea de 17 de diciembre de 1972 (articulo 118): de la URSS de 7 de octubre de 1977 (art. 146), y de la República Popular de China de 5 de marzo de 1978 (art. 36).

(4) J. LASARTE Alvarez: "Potestad legislativa y poder tributario de las Comunidades Autonomas". CIVITAS, Revista Española de Derecho Financiero, nüm. 22 (1979), pág. 216. dice: "Y. además. lo que garantiza el articulo 142 no es la autonomia financiera, sino la suficiencia financiera de las Haciendas locales. que es cosa diferente. aunque la autonomia deba basarse en la suficiencia financiera y conducir a la misma".

El Tribunal Constitucional, en la Sentencia de 2 de febrero de 1981 (antes citada), dice: «La Constitución no garantiza a las Corporaciones locales una autonomia economicafinanciera en el sentido de que dispongan de medios propios - patrimoniales y tributarios - suficientes para el cumplimiento de sus funciones. Lo que dispone es que estos medios serán suficientes, pero no que hayan de ser en su totalidad propios, asi lo expresa con toda claridad el articulo 142 de la Constitución al decir que las Haciendas locales deberán disponer de los medios suficientes para el desempeño de las fun- 
Conviene tener en cuenta al respecto, que el artículo 137 de la Constitución prevé que tanto los Municipios y las Provincias como las Comunidades Autónomas, «... gozan de autonomía para la gestión de sus respectivos intereses». De este precepto se deduce que las Corporaciones locales gozan de autonomía y para ello se requiere una solidez financiera, pues, en otro caso, se estaría ante una pseudoautonomía.

No podemos detenernos aquí en el análisis comparativo del poder financiero, según prefieren varios autores, del poder tributario de las Corporaciones locales y de las Comunidades Autónomas (5), sino que admitimos el poder derivado y no originario para las Corporaciones locales.

Lo que interesa en este trabajo es tratar de perfilar de qué forma y por qué cauces las Corporaciones locales han de gozar de los medios suficientes para el desempeño de las funciones que la Ley les atribuye (art. 142 de la Constitución).

La forma y vías para obtener los recursos necesarios las Corporaciones locales, según el artículo 142 de la Constitución, serán de dos tipos: unos fundamentales y prioritarios, tanto cualitativa como cuantitativamente, y otros que no presentan tales caracterés (6).

El artículo 142 de la Constitución establece que la suficiencia de medios se nutrirá "fundamentalmente de tributos propios y de

ciones que la Ley atribuye a las Corporaciones locales respectivas y que se nutriran fundamentalmente de tributos propios y de la participacion en los del Estado y $\mathrm{Co}$ munidades Autonomas. En consecuencia. dadas las diversas fuentes que nutren a las Haciendas locales. asi como su complementariedad. es aqui plenamente explicable la existencia de controles de legalidad. tanto en relacion con la obtencion y gestion de ingresos de caracter propio como con la utilización de los procedentes de otras funntes". J. MARTIN QUFRALT: "La autonomia municipal en la jurisprudencia del Tribunal Constitucionat". CIVITAS, Revista Española de Derecho Financiero, numero 35 (1982). pag. 469. dice: "Se margina cualquier duda que aun pudiera quedar al interprete de la Constitucion acerca de la diferente posicion constitucional que ocupan las Comunidades Autonomas y los Entes locales. Es cierto que la autonomia se predica dc ambos tipos de Entes. pero no lo es menos que la diferenciacion, aunque solo sea ratione materiae, es tambien clara. Si bien es cierto que la Constitucion no ha formulado expresis verbis tal diferenciaciön. no lo es menos que de una interpretación sistematica de la misma no es dificil concluir en que la posicion que ocupan ambos tipos de tintidi des es distinta".

(5) Sobre esta cuestion pueden verse los trabajos de J. Lasarte Alvarez: "Po testad legislativa y poder tributario de las Comunidades Autónomas". ob. cit., paginas 214 y ss.. y de J. Ramallo: "Incidencia de la Constitucion Espanola de 1978 en materia de fuentes normativas de las Comunidades Autonomas". en Hacienda y Constilucion, Madrid. Instituto de Estudios Fiscales. 1979. págs. 117 y ss.

(6) O. AlzaGa: La Constitución Española de 1978 (Comentario sistemático), Madrid. Ediciones del Foro. 1978. pag. 840. En su comentario al articulo 142 dice: "La virtual autonomia que se reconoce a Municipios y Provincias para alcanzar su plenitud requiere de los medios economicos necesarios". 
participación en los del Estado y de las Comunidades Autónomas" (7).

Según este precepto, las dos fuentes más importantes de recursos financieros de las Corporaciones locales serán las que procedan de tributos propios y de participación en los tributos del Estado y de las Comunidades Autónomas.

Dos ideas pueden extraerse rápidamente: una, que los ingresos más importantes de las Haciendas locales deberán ser de naturaleza tributaria, y otra, que tanto el Estado como las Comunidades Autónomas vienen obligados a actuar en este sentido o, en su caso, permitir que así sea. Se trata de una norma constitucional que debe ser acatada y desarrollada en la forma prevista.

Semejante precepto plantea diversos problemas en orden al respeto de las fuentes de ingresos de cada Entidad pública, y si esto no fuese posible o conveniente, a subsanar o compensar las alteraciones en las fuentes de ingresos de las Corporaciones locales y siempre bajo la perspectiva de respetar principalmente los cauces fundamentales de ingresos.

Para completar estas ideas se hace necesario desarrollar las siguientes cuestiones: 1) Cuáles son las características y naturaleza de la autonomía financiera de las Corporaciones locales. 2) Qué significado puede atribuirse a los recursos de las Corporacionĕs locales que no están comprendidos entre los que la Constitución califica de fundamentales. 3) Cómo debe subsanarse cualquier alteración en los recursos fundamentales por parte del Estado y de las Comunidades Autónomas.

A continuación trataremos de desarrollar cada una.de estas cuestiones.

\section{NATURALEZA Y CARACTERISTICAS DE LA AUTONOMIA FINANCIERA DE LAS CORPORACIONES LOCALES}

Que se hable de autonomía o de suficiencia de medios, el significado es idéntico, al menos en el aspecto material o sustancial (8).

(7) R. Entrena Cuesta. en Comentarios a la Constitución, de F. Garrido Falla y otros. Madrid. Ed. Civitas, S.A.. 1980, pag. 1530. observa: "a) Desde el punto de vista positivo debe destacarse que al disponer que las Haciendas locales "se nutriran fundamentalmente de tributos propios y de la participacion en los del Estado y de las Comunidades Autonomas". no se efectua distincion alguna entre las Haciendas municipal y provincial: lo que podrá llevar en el futuro a suprimir la discriminacion que la legislacion vigente establece en este punto".

(8) J. LASARTE Alvarez: "Potestad legislativa y poder tributario de las Comunir dades Autonomas", ob. cit., pág. 216. cuando matiza la distinción indica que "la 
Es cierto que el Estado y las Comunidades Autónomas tienen poder legislativo y las Corporaciones locales carecen de él (9), pero tal vez para compensar semejante diferencia el legislador constituyente, de categoría superior a los poderes legislativos citados, juzgó oportuno garantizar el respeto a las fuentes fundamentales de las Corporaciones locales por parte de quienes ostentaban, según la Constitución, tales poderes.

En sentido técnico, existe $o$, al menos, late un límite al poder legislativo del Estado y de las Comunidades Autónomas. Si en virtud del poder que les atribuye la Constitución, el Estado o las Comunidades Autónomas afectasen o vulnerasen lo previsto en el artículo 142 de dicho texto, vendrán obligados a restablecer el equilibrio de recursos de los Entes locales y por los medios en él previstos (10).

Este artículo tiene un trasfondo de respeto a la autonomía financiera de los Entes locales, a pesar de que tanto el Estado como las Comunidades Autónomas deban velar por la tutela jurídico-financiera de los citados Entes. La tutela financiera de las Corporaciones locales por parte del Estado resulta de lo previsto en los artículos $137,140,141,142$ y $149,1,18 .^{\circ}$, y la tutela por parte de las Comunidades Autónomas se deduce de los artículos 148, 1, 2. ${ }^{\circ}$, y 152, 3, de la Constitución, y además se prevé en los Estatutos de las distintas

autonomia debe basarse en la suficiencia financiera y conducir a la misma». Por otra parte. la Ley Organica 8/1980. de 22 de septiembre. de Financiacion de las Comunidades Autonomas, en su articulo $20^{\circ}$ dispone: «l. La actividad financiera de las Comunidades Autonomas se ejercera en coordinacion con la Hacienda del Estado. con arreglo a los siguientes principios... d) La suficiencia de recursos para el ejercicio de las competencias propias de las Comunidades Autonomas".

(9) F. Garrido Falla: Comentarios a la Constitución, ob. cit., pág. 1488. Después de referirse a la autonomia de las Comunidades Autonomas, dice lo siguiente: "En cambio. la autonomia que se atribuye a los Entes locales tiene un caracter más limitado: se trata de dejar establecida su sustantividad y plena personalidad juridica para el cumplimiento de sus fines. Unos fines que, por otra parte, a diferencia de lo que ha ocurrido en alguna fase de nuestra evolucion constitucional, no se les reservan a la Constitucion. sino que vendran atribuidos por la legislacion ordinaria. Con la consecuencia de que. desde el punto de vista constitucional, no podra hablarse de unas funciones propias de los Municipios o de las Provincias. ya que solo dispondrán de aquellas funciones que les sean asignadas por el legislador ordinario".

(10) Creemos que la autonomia financiera de los Entes locales se da de distinta forma y no con menos importancia que la de las Comunidades Autonomas. No nos parecen muy acertadas las palabras de L. M. Cazorla PRIETO: El control de las Corporaciones locales por el Tribunal de Cuentas, Madrid, Instituto de Estudios de Administracion Local. 1982. cuando en la pagina 48 dice: "Nos encontramos ante la consagracion del principio de autonomia financiera de las Corporaciones locales, aunque no con la misma fuerza que cuando se lleva a cabo en beneficio de las Comunidades Autonomas. La causa de ello quiza resida. ademas de la consideracion secundaria que los Entes locales han recibido en la Constitucion de 1978. en que el grado de poder politico que confiere el ordenamiento constitucional a los Entes autonomicos es superior al que atribuye a las Corporaciones locales". 
Comunidades Autónomas (11) e incluso en la Ley Orgánica 8/1980, de 22 de septiembre, de Financiación de las Comunidades Autónomas, cuando en su artículo $6 .^{\circ}$, número 3 (12), se permite a éstas establecer tributos sobre las materias reservadas por la legislación local a las Corporaciones locales, y en los supuestos y términos previstos en dicha legislación se exige que se compensen de forma que no se mermen de presente ni de futuro los ingresos. Pero además, la compensación deberá hacerse a tenor de lo previsto en el artículo 142 de la Constitución, como más adelante veremos.

Todo lo cual induce a extraer unas consideraciones en torno a la naturaleza y características de la autonomía financiera de las Corporaciones locales.

La autonomía financiera de los Entes locales presenta una naturaleza diferente de la autonomía del Estado y de la autonomía de las Comunidades Autónomas. Se trata de una autonomía jurídicopública que se manifiesta a través de una suficiencia de medios para atender las competencias propias de los Entes locales, y matizada por una tutela constitucional, que obliga al Estado, en primer lugar, y a las Comunidades Autónomas, en segundo, a respetar y desarrollar normativamtente una esfera de acción, de medios y recursos

(11) Asi, el articulo 48, y por reenvio, los articulos 8 y 9 del Estatuto de Autonomia de Cataluna (Ley Orgánica 4/1979, de 18 de diciembre); articulo 10, 4, del Estatuto del Pais Vasco (Ley Organica 3/1979, de 18 de diciembre); articulos 49 y 27, 2, del Estatuto de Autonomia de Galicia (Ley Orgánica 1/1981, de 6 de abril); articulos 62 y 13, 3, del Estatuto de Autonomia de Andalucia (Ley Orgánica 6/1981, de 30 de diciembre); articulo 11, a), del Estatuto de Autonomia de Asturias (Ley Orgánica $7 / 1981$, de 30 de diciembre); articulo 51 del Estatuto de Autonomía de Cantabria (Ley Organica 8/1981, de 30 de diciembre); articulos 2, 5, 9, 25 y 26 del Estatuto de Autonomia de La Rioja (Ley Orgánica 3/1982, de 9 de junio); articulos 18 y 51 del Estatuto de Autonomia de Murcia (Ley Orgánica 4/1982, de 9 de junio); articulos 44, 45, 46 y 49 del Estatuto de Autonomia de Valencia (Ley Orgánica 5/1982, de 1 de julio); articulos $5 ; 35,1,2 . \circ ; 45$, y 53, del Estatuto de Autonomia de Aragon (Ley Organica $8 / 1982$, de 10 de agosto); articulos $29 ; 30 ; 32$, 1, y 48, del Estatuto de Autonomia de Castilla-La Mancha (Ley Orgánica 9/1982, de 10 de agosto); articulos 29, 2; 32, 57 y 60, del Estatuto de Autonomia de Canarias (Ley Orgánica 10/1982, de 10 de agosto); articulos 4, 18 y 46 del Estatuto de Reintegración y Amejoramiento del Regimen Foral de Navarra (Ley Orgánica 13/1982, de 10 de agosto); articulos 8 y 62 del Estatuto de Autonomia de Extremadura (Ley Orgánica 1/1983, de 25 de febrero); artículos 5, 10 y 66 del Estatuto de Autonomia de las Islas Baleares (Ley Organica $2 / 1983$, de 25 de febrero); articulos 3, 26 y 57 del Estatuto de Autonomia de Madrid (Ley Organica 3/1983, de 25 de febrero); articulos 19 y 41 del Estatuto de Autonomia de Castilla-León (Ley Orgánica 4/1983, de 25 de febrero).

(12) En este precepto se dispone lo siguiente: «3. Las Comunidades Autonomas podran establecer y gestionar tributos sobre las materias que la legislación de Régimen local reserve a las Corporaciones locales, en los supuestos en que dicha legislación lo prevea y en los términos que la misma contemple. En todo caso, deberán establecer las medidas de compensacion o coordinación adecuadas en favor de aquellas Corporaciones, de modo que los ingresos de tales Corporaciones locales no se vean mermados ni reducidos tampoco en sus posibilidades de crecimiento futuro". 
económicos, de los cuales unos son fundamentales. Además, los Entes locales tienen gran margen de actuación en el ámbito del presupuesto y de los gastos públicos.

Muchas y diversas son las características que se pueden señalar a la autonomía financiera de los Entes locales, y de las cuales podemos resaltar las siguientes:

1. ${ }^{a}$ El poder financiero de las Corporaciones locales es un poder derivado, tanto porque éstas carecen de poder legislativo y todo lo concerniente a la reserva de Ley en materia tributaria debe ser cubierto por el poder legislativo de otros Entes, como porque de la Constitución Española así se deduce a tenor de lo dispuesto en los artículos 133, 2 y 4, y 142 (13).

2. ${ }^{\text {a }}$ Las Corporaciones locales tienen garantizada su autonomía financiera por normas de Derecho público en su diversa jerarquia.

3. ${ }^{\mathrm{L}} \mathrm{La}$ autonomía financiera de las Corporaciones locales exige y se basa en una suficiencia de medios para atender las funciones de las mismas. Exige porque la Constitución en su artículo 142 así lo dispone, y consiste en tal suficiencia porque toda autonomía financiera implica la disposición de los recursos necesarios para atender los fines del Ente público que goza de ella (14).

$4{ }^{\text {a }}$ La autonomía financiera goza de una tutela prevista a nivel constitucional que no se debe canalizar tanto por la vía del puro y simple deber del Estado (15) y de las Comunidades Autónomas,

(13) Dejando a un lado el tema del poder financiero de las Comunidades Autónomas, de una comparación de los articulos $133,1,2$ y 4, y 142 de la Constitución, se deduce que las Corporaciones locales pueden establecer tributos y otros recursos con sujecion a la Constitución y a las Leyes, luego su poder depende de otro, ya que, por otra parte, carecen de poder legislativo. El articulo 133, en sus apartados 1, 2 y 4 , dispone: " 1 . La potestad originaria para establecer los tributos corresponde exclusivamente al Estado mediante Ley. 2. Las Comunidades Autonomas y las Corporaciones locales podrán establecer y exigir tributos de acuerdo con la Constitución y las Leyes. ...4. Las Administraciones Püblicas solo podran contraer obligaciones financieras y realizar gastos de acuerdo con las Leyes". En cambio, el numero 3 de dicho articulo parece que deja un tanto a salvo lo relativo a los beneficios fiscales que no afecten a los tributos del Estado, pero por tratarse de una cuestion sometida al principio de reserva de Ley (vid. art. 31) tendriamos que reconducir el poder tributario de las Corporaciones locales a lo expresado anteriormente.

(14) El Estado tiene conciencia de esa necesidad y asi se deduce, entre otras disposiciones, de un parrafo de la Exposición de Motivos de la Ley 24/1983, de 21 de diciembre, que dice asi: "Por ello es firme proposito resolver la cuestion definitivamente. mediante un conjunto de medidas concretas que responden al mandato constitucional de autonomia y suficiencia, y que culminarán con la presentación a las Cortes Generales de la Ley de Financiacion de las Entidades locales".

(15) Esta tutela aparece muy fortalecida en la Ley Orgánica del Estado de 1 de enero de 1967, cuando en su articulo 47 disponia: «El Estado promueve el desarrollo de la vida municipal y provincial, protege y fomenta el patrimonio de las Corporaciones 
cuanto per el derecho o derecho-poder de las Corporaciones locales a exigir que el Estado y las Comunidades Autónomas desarrollen de la forma más o menos establecida la suficiencia de medios de los Entes locales. Si las Corporaciones locales carecen de poder legislativo, tienen en compensación el derecho-poder (un poder resorte) a que se legisle para que gocen de los recursos necesarios. El hacer valer este derecho-poder dependerá de las circunstancias que concurran en cada caso, y podrán ser de diversa naturaleza: políticas, a través de los representantes en las Cortes, y jurisdiccionales, ante el Tribunal Constitucional e incluso del Poder ejecutivo mediante un coordinado desenvolvimiento de competencias y de exigencias.

5. ${ }^{\text {a }}$ Para que la autonomía financiera tenga una solidez genuinamente local, se prevé en la Constitución que los recursos fundamentales provengan de tributos propios y de participación en los del Estado y de las Comunidades Autónomas (16). En este caso, debe entenderse de la participación en los tributos del Estado y de las Comunidades Autónomas exigidos en virtud de hechos imponibles realizados en los territorios de las Entidades locales, sin perjuicio de las transferencias que puedan resultar del Fondo Nacional de Cooperación Municipal o de instituciones análogas, que se nutrirán de fuentes de recursos financieros con un carácter más globalizado (17). Será discutible si pueden comprenderse entre los recursos fundamentales la participación globalizada a través de dicho Fondo, pues parece que el artículo 142 de la Constitución presente un espíritu más directo de propios, ya que cita en primer lugar los tributos propios y por ello debe entenderse la participación más ligada a la realización del tributo del Estado y de la Comunidad Autónoma en el territorio del Ente local. Además, el Fondo tiene también otros fines, como reducir el desequilibrio de unos Entes municipales respecto de otros. Pero esta interpretación, acomodada al ámbito territorial del hecho imponible, puede perjudicar a los Municipios pequeños y donde exista desequilibrio económico, y puede corregir-

locales y asegura a éstas los medios economicos necesarios para el cumplimiento de sus fines". Precepto este que correspondio a un modelo centralista.

(16) R. EnTREna Cuesta, en Comentarios a la Constitucion, ob. cit., pág. 1529. dice: "El precepto que tratamos consta de dos partes: la primera, en que proclama el principio de autosuficiencia financiera, y la segunda, en que establece los medios de que fundamentalmente se nutriran las Haciendas locales para conseguir dicha autosuficiencia".

(17) Sobre la integración de los recursos en este Fondo, pueden verse las Leyes de Presupuestos del Estado, y concretamente para 1984, el articulo 13 de la Ley 44/1983. de 28 de diciembre, de Presupuestos Generales del Estado para 1984. 
se precisamente con fuentes complementarias, como el Fondo Nacional de Cooperación Municipal (18).

Los demás ingresos que veremos más adelante, sin mermar su importancia, no tienen el carácter de fundamentales. Por ello, si los Entes locales (incluso el problema podría plantearse respecto de cada uno) observasen que cualitativa y cuantitativamente o sólo cuantitativamente no se nutrieran sus ingresos fundamentalmente de los tributos propios y de la participación en los tributos del Estado y de las Comunidades Autónomas, podrán o incluso deberán instar de estos Entes que prevean lo oportuno de forma adecuada para que se cumpla el artículo 142 de la Constitución en orden a que se respeten sus ingresos fundamentales de acuerdo con ésta.

También puede suceder que esta interpretación del artículo 142 de la Constitución pueda aparentemente perjudicar a Entes locales con desequilibrio económico o a los más pequeños, pero para corregir esto existen otras vías, cuyos mecanismos y formas de actuación vienen previstos por la Constitución, tanto a nivel estatal como a través de las Comunidades Autónomas y también vía Corporaciones locales (19).

$6{ }^{a}$ En lo que concierne al presupuesto y al gasto público, las Corporaciones locales tienen mayor margen de actuación, si bien en el artículo 133, 4, de la Constitución se prevé la sumisión de las Administraciones públicas a la Ley en lo referente a contraer obligaciones y realizar gastos (20).

(18) En este sentido, puede citarse el último párrafo de la Exposición de Motivos de la Ley 24/1983, de 21 de diciembre, que dice asi: "Estas últimas medidas al tiempo que permiten obtener mayores ingresos para las Corporaciones locales y responsabilizar a estas en cuanto a su esfuerzo fiscal, haciendolas soportar el coste psicológico y politico que todo aumento de presion fiscal supone, son el correlativo complemento del incremento de la participacion de los Ayuntamientos en los ingresos del Estado a traves del Fondo Nacional de Cooperacion Municipal, que se ha incluido en la Ley de Presupuestos Generales del Estado para 1983, y que constituyen fiel exponente de la firme y decidida voluntad del Gobierno de la Nacion de hacer efectivo, a la mayor brevedad posible, el mandato constitucional de que las Haciendas locales dispongan de los medios suficientes para el desempeño de las funciones que la Ley atribuye a las Corporaciones locales, con plena autonomia para la gestion de sus intereses".

(19) Las medidas y mecanismo son de diversa indole, como puede deducirse de la Constitución. entre otros, de los siguientes articulos: 2, 138, 156 y 158 (principio de solidaridad): 31 (sistema tributario inspirado en los principios de capacidad económica, igualdad y progresividad, que sea justo y racional y no tenga alcance confiscatorio y asignación equitativa a través del gasto público); 40,131 y 138 (promoción por parte de los poderes publicos del progreso social, equitativa y justa distribución de la renta regional y personal, equilibrar el desarrollo regional y sectorial y estimular el crecimiento de la renta y de la riqueza).

(20) El mayor margen de actuación de las Corporaciones locales en materia de presupuesto y gasto público puede verse en la Ley 40/1981, de 28 de octubre, y en 
7. ${ }^{\text {a }}$ La autonomía financiera que se deduce del artículo 142 de la Constitución exige para las Administraciones públicas un modelo de financiación múltiple descentralizado (21). Para operar el cambio de modelo actual (con grandes dosis de centralización y, sobre todo, de falta de armonización entre los sistemas tributarios estatal y local) es preciso aumentar la imposición, o mejor, la tributación autónoma, y disminuir las transferencias del Estado a los Entes locales (22). El sistema de transferencias, que responde más a un modelo centralizado, implica no sólo cierto coste financiero, sino que además hace que determinados Municipios no perciban por vía de tributos el coste de actividades, de obras, de cesiones de dominio y de prestaciones de servicios, es decir, mediante contribuciones especiales y tasas, desperdiciándose unas fuentes tributarias que además de ser correctas, su exacción implica evitar ciertos desequilibrios municipales o respecto de otras Entidades locales.

Se impone, pues, la necesidad de una Ley de Financiación de las Entidades locales, en la que se prevea la suficiencia ponderada de medios de dichas Entidades a la luz de principios como el de capacidad de pago, igualdad, progresividad y asignación equitativa de los recursos públicos (23). La cual vendría no sólo a establecer una

cierta medida en la Ley $24 / 1983$, de 21 de diciembre, de Medidas Urgentes de Saneamiento y Regulación de las Haciendas locales.

(21) R. Entrena Cuesta, en Comentarios a la Constitución, ob. cit., pág. 1530: "De nada serviria, en efecto, la consagracion de dichos principios si las Haciendas locales no fuesen autosuficientes para alcanzar sus fines. Pues o habrian de renunciar a ejercitar las funciones de su competencia, con lo que la descentralizacion y la autonomia se volverian, en definitiva, en contra de los ciudadanos, que carecerian de los servicios necesarios, o habrian de acudir a la ayuda de otros Entes por la via de la subvención: con lo que, si bien se mejoraria la prestación de servicios, se produciria una erosion de los principios de referencia al posibilitarse, mediante aquellas, una penetración del sujeto subvencionante en la gestion de la Corporación subvencionada".

(22) L. M. CAZORLA PRIETO: El control de las Corporaciones locales por el Tribunal de Cuentas, ob. cit., pág. 38. Este autor trata de dar un sentido al aumento de las transferencias en los siguientes terminos: "En este contorno economico-social las transferencias del Estado son cada vez más voluminosas. El Estado, en sentido estricto, se convierte poco a poco en financiador de las actividades de los Entes territoriales. Proceso agravado por el hecho de que los principales instrumentos de financiacion, tributos personales sobre la renta, están en manos de aquél».

Con el texto de la Constitución en la mano nos parece digna de mención la opinión de R. Entrena. Cuesta, en Comentarios a la Constitución, ob. cit., pág. 1530, cuando dice: «b) En sentido inverso, es de hacer notar que, como ya apuntamos anteriormente, no se contempla la subvención entre los recursos con que contarán, fundamentalmente, las Haciendas locales. Lo cual no quiere decir, desde luego, que se excluyan, dados los términos en que el articulo esta redactado; pero si que de acudirse a tal ingreso, debera hacerse de forma secundaria y excepcional: como medio, precisamente, de proteger la autonomia de la Corporación que lo reciba, o, en su caso, instrumentando un sistema de otorgamiento que permita el respeto a dicha autonomian.

(23) J. MARTÍN QueralT: "La autonomia municipal en la jurisprudencia del Tribunal Constitucional», ob. cit., pág. 469, dice: "El principio de autonomia no puede 
coordinación de los sistemas tributarios de las Administraciones públicas, sino también a lograr una racionalidad del sistema financiero y tributario global o conjunto de dichas Administraciones, tan necesaria en nuestro país (24).

Sólo con una correcta armonización del sistema tributario y financiero de las Administraciones públicas (25) se puede lograr el cumplimiento de los principios-previstos en el artículo 31 de nuestra Constitución, y se podría ofrecer la base necesaria para hacer plenamente viable el principio de solidaridad.

\section{SIGNIFICADO QUE PUEDE ATRIBUIRSE A LOS RECURSOS DE LAS CORPORACIONES LOCALES QUE NO ESTAN COMPRENDIDOS ENTRE LOS QUE LA CONSTITUCION CALIFICA DE FUNDAMENTALES}

A los recursos de las Corporaciones locales que no consistan en tributos propios y en participaciones en los tributos del Estado y de las Comunidades Autónomas, que son los que considera la Constitución como fundamentales, habrá que atribuirles una menor importancia. Su consideración plantea ciertos problemas de tipo cualitativo y cuantitativo. De tipo cualitativo porque pueden existir cir-

oponerse al de unidad, sino que es precisamente dentro de este donde alcanza su verdadero sentido. Conclusion textual cuya importancia en el ámbito juridico tributario es innecesario subrayar, a efectos, sobre todo, de hacer operativos los principios de justicia material. recogidos en el articulo 31 de la Constitucion". L. M. CAzorLA PRIETO: El control de las Corporaciones locales por el Tribunal de Cuentas, ob. cit., pagina 62. dice: "El postulado de justicia material en el gasto público completa el correspondiente al tributo y ambos redondean el mismo principio en todo el campo financiero. Por ello es correcto que si el referente al tributo se formula en el apartado 1 del articulo 31 de la Constitucion, el circulo se cierre respecto al gasto público en el apartado 2 del mismo precepto".

(24) J. CAPDEvila Salva: "La fundamentación normativa de la autonomia (principios generales) (Los sistemas fiscales multiples)", Revista de Hacienda Autonómica 1 Local, num. 36 (1982). pág. 534, dice: "En consecuencia, dentro de la autonomia local. el primer problema financiero que surge en relación con los ingresos locales es el de reparto y coordinación de las distintas figuras fiscales entre los niveles de la Hacienda. Sc trata de un importante aspecto desde la perspectiva fiscal, que por las repercusiones que puede tener hay que enfocar inicialmente de la mejor forma posible".

(25) Hay que tener en cuenta que es importante el peso financiero de las Corporaciones locales en el sector püblico general. G. SOLE VILLALONGA: "El orden constitucional y el sistema fiscal", ob. cit., pág. 126, observa lo siguiente: "Tengo delante de mi las cifras del Presupuesto - que ya se elabora en España- del conjunto de estas cuatro Administraciones publicas. Pues bien, en el Presupuesto para este año 1977. la Administracion Central del Estado no llega al 50 por 100 del Presupuesto de las Administraciones públicas. Por tanto. referirnos al Estado es referirnos a una parte, pero solo a una parte. Creo que es mucho más correcto, y luego aportare más argumentos. referirnos al conjunto de las Administraciones püblicas". 
cunstancias especiales en las que las Corporaciones locales o bien tienen que acudir a ingresos extraordinarios (Deuda pública) o bien poseen fuertes patrimonios $o$ se intenta subsanar una situación arrastrada, surgiendo disposiciones como la Ley 24/1983, de 21 de diciembre, de Medidas Urgentes de Saneamiento y Regulación de las Haciendas locales, que pretenden salvar una situación de desequilibrio de éstas mediante la financiación por el Estado a través de la subvención.

En tales situaciones habrá que reconsiderar el significado de dichos ingresos y su relación con los que la Constitución considera fundamentales.

Desde el punto de vista cualitativo, no puede entenderse que, en términos absolutos, siempre han de ser mayores los ingresos que se consideran fundamentales por la Constitución, pues ello nos llevaría a situaciones extremas que carecerían de jutificación, al menos desde un punto de vista de la realidad práctica.

$\mathrm{Si}$ se adopta la postura de que siempre y en cada Ente local deben ser superiores a otros ingresos los tributos propios y la participación en los tributos del Estado y en los de las Comunidades Autónomas, nos encontraríamos con Entes locales que gozarían de ingresos desproporcionadamente superiores a los de otros Entes. Como ejemplo podría citarse el de aquellos Entes locales que tuviesen rendimientos de Derecho privado o ingresos patrimoniales muy cuantiosos en relación con su volumen financiero. En estos casos sería desproporcionado establecer tributos propios de forma que superasen tales ingresos o que las participaciones en los tributos del Estado y de las Comunidades Autónomas fuesen también superiores. De hacerse así podriamos encontrarnos con una situación absurda no sólo porque se lograría un volumen de ingresos muy superiores a los normalmente necesitados, sino también porque incidiria en una mayor tributación de los residentes en la localidad, especialmente cuando se estableciesen tributos propios superiores a los necesitados, aunque sólo fuese en la cuantía que demandase su proporcionalidad respecto de otros ingresos, pues no dejaria de ser una situación anormal.

Por estas razones entendemos que el artículo 142 de la Constitución está indicando que con carácter general, salvadas las excepciones que puedan darse, los ingresos fundamentales de las Corporaciones locales deberán ser los tributos propios y la participación en los tributos del Estado y en los de las Comunidades Autónomas. 
Esta interpretación del citado precepto se acomoda más a criterios lógicos y teleológicos que a los puramente gramaticales.

Además, no se daña a la autonomía financiera, puesto que no puede ponerse en tela de juicio que quien tiene fuertes ingresos patrimoniales no pueda gozar de sana y auténtica autonomía financiera.

Por otra parte, los principios de igualdad, capacidad económica y solidaridad fundamentan tal interpretación, entendidos éstos en sus aspectos activo y pasivo. Es decir, no se podría dejar de gravar, al menos en tributos más generales, a los residentes en un Ente local con fuertes ingresos patrimoniales ni tampoco ser más gravados, pues lo demanda su capacidad económica, la igualdad ante la Ley y cierta solidaridad interterritorial.

Una vez hechas estas precisiones, sólo nos queda formular de forma sencilla y clara cuáles serían los ingresos que no incluye el artículo 142 de la Constitución entre los que nutrirán fundamentalmente las Haciendas locales.

Para lo cual consideramos oportuno traer a colación lo dispuesto en el artículo $1 .^{\circ}$ de las Normas provisionales para la aplicación de las Bases 21 a 24 de la Ley $41 / 1975$, de 19 de noviembre, referentes a los ingresos de las Corporaciones locales, aprobadas por Real Decreto $3250 / 1976$, de 30 de diciembre, que dice así: «1. La Hacienda de los Municipios estará constituida por los siguientes recursos: a) Ingresos de Derecho privado. b) Subvenciones y otros ingresos de Derecho público. c) Tasas. d) Contribuciones especiales. e) Imposición municipal-autónoma. f) Recargos sobre impuestos estatales. g) Participación en impuestos estatales. h) Ingresos procedentes de operaciones de crédito. i) Tributos con fines no fiscales. j) Multas. 2. Los Municipios que no reúnan las condiciones establecidas podrán imponer también la prestación personal y de transporte» (26).

Este precepto es el que, en relación con las Corporaciones locales, establece un abanico más amplio de ingresos (27).

(26) Observese que por ser anterior a la Constitución y a la LOFCA no recoge los recargos y las participaciones en los tributos de las Comunidades Autonomas.

(27) Con menor variedad de fuentes de ingresos, el articulo 128 establece los recursos de las Entidades locales menores, el articulo 129 los de las Mancomunidades y Agrupaciones municipales y de los Consorcios y el articulo 130 los de la Hacienda provincial. Dichos preceptos rezan asi: Articulo 128: "1. La Hacienda de las Entidades locales menores estara constituida por los siguientes recursos: a) Ingresos de Derecho privado. b) Subvenciones y otros ingresos de Derecho público. c) Tasas. d) Contribuciones especiales. e) Ingresos procedentes de operaciones de crédito. $f$ ) Tributos con fines no fiscales. $g$ ) Multas. 2. Seran aplicables a los recursos relacionados con el numero anterior las disposiciones de los capitulos correspondientes sobre las Haciendas municipales, con las adaptaciones derivadas del carácter de ingresos propios 
De todas estas fuentes de ingresos, sin perjuicio del significado financiero que tiene la prestación personal y de transporte en aquellos Municipios (hasta 10.000 habitantes) en que se permite su establecimiento, serían ingresos que no pueden considerarse como los que han de nutrir fundamentalmente las Haciendas locales, los siguientes: a) Los ingresos de Derecho privado. b) Las subvenciones y otros ingresos de Derecho público. c) Los ingresos procedentes de las operaciones de crédito. d) Los tributos con fines no fiscales (28). e) Las multas.

Las tasas, las contribuciones especiales, la imposición municipal autónoma y los recargos sobre impuestos estatales constituyen lo que pudiéramos denominar tributos propios. Las participaciones en impuestos estatales son el otro concepto de ingresos fundamentales de las Haciendas locales, según el artículo 142 de la Constitución. Algo semejante puede decirse de otros Entes locales.

de las Entidades locales menores que tienen los mismos. 3. Las Entidades locales menores podrán imponer la prestación personal y de transporte de acuerdo con las mismas normas establecidas para los Ayuntamientos. 4. No procederá tal imposición por las Entidades locales menores cuando la tuviere acordada el Ayuntamiento con carácter de generalidad". Articulo 129: "1. La Hacienda de las Mancomunidades y Agrupaciones municipales y de los Consorcios estara constituida por los siguientes recursos: a) Ingresos de Derecho privado. b) Subvenciones y otros ingresos de Derecho público. c) Tasas. d) Contribuciones especiales para la ejecución de obras o para el establecimiento y ampliación o mejora de servicios de la competencia de dichas Entidades. e) Los procedentes de operaciones de crédito. f) Las multas. 2. Serán de aplicación a las mencionadas Entidades lo dispuesto en el Titulo I de estas normas respecto de los ingresos a que se refiere el numero anterior. 3. Tambièn constituirản recursos de estas Entidades las aportaciones de los Municipios, en su caso Diputaciones que integren o formen parte de las mismas. Dichas aportaciones serán determinadas de acuerdo con lo establecido en los Estatutos respectivos". Articulo 130: "La Hacienda de las Provincias estara constituida por los siguientes recursos: a) Ingresos de Derecho privado. b) Subvenciones y otros ingresos de Derecho publico. c) Tasas. d) Contribuciones especiales. e) Recargos sobre impuestos estatales. f) Participacion en impuestos estatales. g) Ingresos procedentes de operaciones de crédito. h) Tributos no fiscales. i) Multas». De forma semejante se pueden ver los articulos 106,110 y 111 del Proyecto de Ley, por el que se aprueban las Bases de la Administración local (Boletín Oficial de las Cortes Generales, Congreso de los Diputados, Serie A, de 25 de mayo de 1981, num. 196-1). Aunque en este Proyecto no se incluyen entre los tributos propios (art. 108) los recargos sobre impuestos del Estado y de las Comunidades Autónomas, sin embargo parece que tampoco los excluye expresamente al tratarlos en el articulo siguiente por razón de mejor sistemática y una regulación más detallada, aunque tambien se separan en el articulo 106 al referirse primero a los tributos propios y despues a los recargos. No se incluyen en el articulo 106 los tributos con fines no fiscales, por lo que parece que quedarian fuera de los recursos de los Entes locales.

(28) Entendemos que los tributos con fines no fiscales están llamados a cumplir fines no recaudatorios y por ello parece que no encajan bien en el concepto de tributos propios, aunque no dejan de ser tributos de los Entes locales. 


\section{COMO DEBE SUBSANARSE CUALQUIER ALTERACION EN LOS RECURSOS FUNDAMENTALES POR PARTE DEL ESTADO Y DE LAS COMUNIDADES AUTONOMAS}

La primera cuestión que se plantea es la de determinar si alguno de los recursos mencionados en el artículo 142 tiene un carácter fundamental más pronunciado o si la fundamentalidad corresponde de forma indivisible a ambos.

Pensamos que atendiendo a una autonomía financiera basada en los ingresos públicos, sin perjuicio de la autonomía en el gasto público, nos conduciría, a través de una interpretación sistemática (29), a considerar como fundamentales de primer grado a los tributos propios (30).

Tales tributos propios serian, en principio, las tasas, las contribuciones especiales y los impuestos (31). También, aunque sea de una forma más impropia, en cuanto a la autonomía o independencia

(29) Asi se puede deducir de una comparación de los articulos 156,157 y 158 de la Constitucion respecto de las Comunidades Autonomas. N. D"AMATI: "La autonomia impositiva de los Entes locales en Italia: aspectos historicos y juridicos", Revista de Hacienda Autonómica y Local, num. 37 (1983), pág. 34, admite que historicamente se demuestra que es bueno disociar los gastos de los ingresos para lograr una adecuada autonomia de los Entes locales.

(30) Por otra parte. asi viene entendido por las Cortes Generales, como puede deducirse de preceptos como el articulo 17, 3, de la Ley 40/1981. de 28 de octubre, de Regimen Juridico de las Corporaciones locales, que dice asi: "La Administracion del Estado podrá comprobar el destino dado por las Corporaciones locales a los fondos procedentes de asignaciones presupuestarias y de participacion en los ingresos tributarios del Estado. el grado de utilización de sus recursos tributarios propios y el nivel de prestacion de 'los servicios publicos de caracter basico". Y de forma mas clara parece evolucionar la legislación en el Proyecto de Ley por el que se aprueban las Bases de la Administracion local (Boletin Oficial de las Cortes Generales, Congreso de los Diputados. Serie A. de 25 de mayo de 1981, núm. 196-I), que en el articulo 112, 2, dice: "Se estableceran límitaciones en la participación en los impuestos del Estado para aquellas Entidades en que concurra alguna de las siguientes circunstancias: a) Que no utilicen todos los recursos tributarios que tengan autorizados. b) Que el rendimiento de los recursos establecidos no cubra los costes de prestación de los servicios. de la realizacion de actividades o el valor del aprovechamiento por la utilizacion privativa o especial de su dominio público. 3. Para establecer tales limitaciones. la Administración del Estado deberá instruir el oportuno expediente, dando audiencia a la Entidad interesada. La resolución que se dicte agotará la via administrativa y será impugnable ante la jurisdicción contencioso-administrativa".

(31) Estas son las categorias de tributos propios que se incluyen en el articulo 108 del Proyecto de Ley de Bases de la Administración local (antes citado). Aunque en el Anteproyecto y en el informe de la ponencia el texto del precepto (actual articulo 142 de la Constitucion) decia "... y se nutriran fundamentalmente de impuestos $y$ tasas propias y de participaciones...", se sustituyó con carảcter más técnico la expresion «impuestos y tasas" por la de "tributos» en virtud de una enmienda in voce del grupo de UCD. por lo que en el dictamen de la Comision del Congreso ya se recoge la redacción actual y que seria aprobada por el Congreso y por el Senado. 
del tributo, se pueden incluir entre los tributos propios, los recargos sobre impuestos del Estado y de las Comunidades Autónomas (32).

Las participaciones en los tributos del Estado y de las Comunidades Autónomas, no pueden considerarse como tributos propios en el sentido antes indicado $y$, además, la Constitución, en su artículo 142, así lo da a entender, y, por otra parte, permite atribuirlos un carácter fundamental de segundo grado, según hemos indicado.

El tema que tratamos se plantea más crudamente cuando la diversidad de Municipios presenta todo un abanico de posibilidades en torno a la suficiencia o no de recursos para atender sus necesidades. Pero no sólo se da esa variedad de tributos según el tipo de Municipio, sino que además se plantea el problema de su capacidad de gestión para la liquidación y recaudación de los mismos.

Por todo ello, resolver en líneas de generalidad la suficiencia o autonomía financiera de los Entes locales resulta comprometida y problemática: mientras que para unos Entes locales resulta adecuada la creación de impuestos propios, para otros, por falta de fuentes adecuadas o por dificultad o imposibilidad de gestión, no presenta la idoneidad nečesaria. Algo parecido puede decirse de los recargos y de las participaciones; pero éstos, por no ser gestionados y recaudados por los Entes locales, el problema radica más en su escasa rentabilidad, por ser reducidas las fuentes de los mismos o porque

(32) Los recargos exigibles sobre las bases o las cuotas presentan la configuracion de exacciones tributarias distintas de la exaccion principal y cada una de ellas tiene su propia y especifica cuota, y no pueden confundirse con la cuota de la exacción principal. Vid. nuestro comentario al articulo 58 de la Ley General Tributaria en Comentarios a las Leyes Tributarias y Financieras, Madrid, Editoriales de Derecho Reunidas, 1982, págs. 486 y ss. M. CORTÉS Dominguez y J. M. a Martín Delgado: Ordenamiento tributario español, 3. a edición, Madrid, Ed. Civitas, S.A., 1977, página 435 , escriben refiriendose a los recargos legalmente exigibles sobre las bases o las cuotas, ya sea en favor del Tesoro o de otros Entes públicos: "Cuando los recargos los percibe un Ente distinto del titular del crédito tributario, entendemos se trata de obligaciones distintas". J. J. FERREIRO LAPATZA: Curso de Derecho Financiero Español,

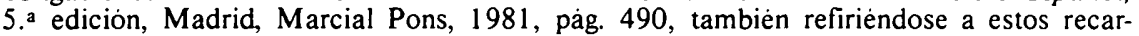
gos, escribe: «a) Puede estar obligado a pagar, simultáneamente, dos obligaciones tributarias. Es lo que ocurre cuando ha de pagar un tributo al Estado y, al mismo tiempo, un tributo de carácter local que figure como recargo del primero. Este recargo no se funde con el tributo estatal, ya que el acreedor no es el Estado, sino otro Ente püblico".

No obstante, en el Proyecto de Ley de Bases de la Administración local, ya citada, los recargos sobre impuestos del Estado y de las Comunidades Autonomas se regulan en un articulo distinto (art. 109) de aquel en el que se prevén los tributos propios (articulo 108), lo que tampoco impide considerarlos como tributos propios, aunque sea de forma más indirecta. 
los índices de asignación en las participaciones no dan los resultados necesarios.

Si se utilizan sistemas de carácter general y de tratamiento cuantitativamente semejante, los resultados pueden ser muy distintos $y$, además, pueden ser peyorativamente discriminatorios para aquellos Entes locales en que está en juego la suficiencia financiera, prevista en el artículo 142 de la Constitución, y con ella su subsistencia.

Entendemos que a la vista del artículo 142 de la Constitución, el poner en peligro la suficiencia financiera de los Entes locales es algo vedado para el Estado y para las Comunidades Autónomas (33;

Dos cuestiones debemos tratar: una respecto de los Entes locales, otra en relación con los administrados de tales Entes.

Respecto de los Entes locales, como ya queda indicado, entendemos que la Constitución, en su artículo 142, les otorga un derechopoder frente a Entes superiores (Estado y Comunidades Autónomas) para poder exigir su autonomía o suficiencia financiera. Este derecho-poder debe ser desarrollado en nuestro ordenamiento juridico y los Entes locales podrán canalizarlo tanto por la vía del desarrollo legislativo, que haga posible su suficiencia financiera, como por la vía jurisdiccional, impugnando ante el Tribunal Constitucional aquellas disposiciones legales que atenten contra tal suficiencia.

Por lo que se refiere al administrado, deben tenerse presentes principios como el de igualdad tributaria, capacidad económica y progresividad y también el de solidaridad (34). No se puede asegurar la suficiencia o autonomía financiera sobre la base de que los habitantes, residentes o quienes realicen actos o actividades en unos Entes locales resulten discriminados tributaria y financieramente,

(33) En este sentido habria que delimitar claramente cuales son los recursos que debieran ser del Estado y de las Comunidades Autonomas. L. M. CAzorLa PRIETO: El control de las Corporaciones locales por el Tribunal de Cuentas, ob. cit., pág. 51, al referirse a la justificacion o no del control financiero por parte del Estado en base a la importancia de las transferencias, dice: "Este argumento, además de ser parcial, ya que tan solo alcanzaria a las transferencias, que si bien son importantes, no lo son todo en el campo del gasto público local; pero algunos olvidan que como fruto, por un lado. del sistema tributario actual, en el que los grandes impuestos recaudados estan en manos del Estado, y, por otro, del creciente número de tareas que, por las razones conocidas, recaen sobre las espaldas municipales y provinciales, tales transferencias son más bien ingresos locales obtenidos por el Estado y, como consecuencia de ello, objeto de transferencias en favor de las Entidades territoriales".

(34) Principios que estan exigiendo un sistema tributario racional y justo y tambien solidario. Estos principios se encuentran amparados por diversos articulos, como pueden ser el 14,31 (igualdad. capacidad economica y progresividad), 2, 138 y 158 (solidaridad) de la Constitución. 
respecto de los que reúnan tales circunstancias en otros, pues se estaria faltando a uno o varios de tales principios.

Todo lo cual nos está indicando que, según los casos, asi será el tratamiento tributario y financiero de los respectivos Entes locales. Siempre, en primer lugar, se debe intentar conseguir la suficiencia financiera a través de los tributos propios, y cuando esto no sea posible o sea perjudicial o atente contra ciertos principios constitucionales, se deberá acudir a participaciones en los tributos del Estado y en los de las Comunidades Autónomas, y si tampoco fuese posible o conveniente, se procurarán por otras vias los ingresos necesarios (35).

La reciente política de permitir recargos sobre los tributos estatales favorece esencialmente a los Entes locales más ricos y con mayores recursos en manos de los ciudadanos, y es poco favorable o perjudicial para los Entes locales en que se den las circunstancias contrarias. En ello también puede incidir en gran medida el nivel de exacción de los tributos alcanzado por los órganos estatales.

Además, hay que hacer la observación de que pueden verse perjudicados tributariamente Entes locales que han padecido o han resultado discriminados por la vía del desarrollo económico y social o en virtud de conductas poco adecuadas para la equitativa distribución de la renta nacional (36). Por ello es necesario habilitar vías de financiación que permitan subsanar o atenuar los defectos que pudieran haber existido en los planos económico, financiero y tributario.

Nos parece correcto indicar que esta suficiencia financiera ha de tener una base en la Ley, es decir, el artículo 142 de la Constitución debe tener el oportuno desarrollo legislativo, tanto por parte del Estado como por parte de las Comunidades Autónomas.

Digo que el Estado y las Comunidades Autónomas, cada cual según sus competencias, deben garantizar mediante Ley el desarro-

(35) J. Capdevila Salvi: "La fundamentacion normativa de la autonomia (principios generales) (Los sistemas fiscales multiples)", ob. cit., pág. 535: "La importancia de la cuestion anterior radica en el hecho de que constituyan el nexo o el puente, si se quiere, que conecta las perspectivas constitucional y funcional de la autonomia, ya que la financiación compartida, además de fruto de un pacto sobre el reparto de ingresos entre los niveles de la Hacienda, es el gran instrumento de que se dispone para corregir los efectos de las externalidades interjurisdiccionales o de la exportación de los tributos, ya sea mediante la aplicacion de un trato distinto, en la recepcion de subvenciones, a las distintas Haciendas, o bien mediante pagos horizontales entre Haciendas locales afectadas".

(36) Véanse, al respecto, los articulos 40,131 y 138 de la Constitución. 
llo del artículo 142 de la Constitución, y lo dében hacer mediante una puesta en marcha de las figuras jurídico-financieras adecuadas. La conducta a seguir por el Estado y por las Comunidades Autónomas debe ser dinámica, es decir, debe adaptarse a las circunstancias de cada momento.

El Estado ha adoptado medidas diferentes, que van desde el establecimiento y modificacion o cesión de tributos propios (37) hasta la creación de recargos y participaciones sobre sus propios tributos (38), sin perjuicio, claro está, de las incesantes transferencias.

Sería muy discutible si las distintas medidas adoptadas por el Estado en cada caso fueron las más adecuadas o las únicamente posibles, atendidas las circunstancias existentes, o si no se dio ni lo uno ni lo otro.

Lo que sí es cierto es que el Estado debe adoptar distintas medidas de financiación de los Entes locales, adaptadas a las circuns-

(37) Por referirnos a etapas recientes, indicaremos que en materia de tenencia y disfrute, los vedados y acotados de caza dejan de tributar por el Impuesto de Lujo y pasan a ser gravados por el Impuesto local de Gastos Suntuarios (vid. Disposicion Final 3.a, 2, de la Ley 41/1975; de 19 de noviembre, y Disposicion Final 1.a del Real Decreto 3250/1976, de 30 de diciembre); algo semejante se puede decir de las cuotas de entrada en sociedades y circulos de recreo.

Por Real Decreto $2 / 1980$, de 11 de enero, sobre medidas economico-fiscales complementarias de la elevación del precio de productos petroliferos, en su articulo $2 .^{\circ}$ suprime el de tenencia y disfrute de automóviles, regulado en el articulo 35 del Texto Refundido de la Ley del Impuesto sobre el Lujo; pero en este caso, la compensacion se hace por la via de una subvención del Estado a los Ayuntamientos con cargo a los Presupuestos Generales del Estado, que será equivalente al importe de la participacion (del 90 por 100) correspondiente al año 1979. Esto, en cambio, no impide que se venga autorizando a los Ayuntamientos la elevación del Impuesto Municipal de Circulación de Vehiculos de Motor (vid. art. 21 de la Ley 40/1981, de 28 de octubre).

Tambien desaparecen en el Impuesto sobre el Lujo la tenencia y disfrute de palacios, hoteles particulares o "chalets", pues no se recoge en la Ley $6 / 1979$, de 25 de septiembre, sobre regimen transitorio de la imposicion indirecta (antes regulados en el articulo 36 del Texto Refundido del Impuesto sobre el Lujo, que ahora se dedica a la regulación de la jurisdicción competente).

En la Ley 44/1978, de 8 de septiembre, del Impuesto sobre la Renta de las Personas Fisicas, en su Disposicion Transitoria 2.a, transforma en tributos locales de caracter real la Contribución Territorial Urbana, la Contribución Territorial Rustica y Pecuaria, la Licencia Fiscal del Impuesto Industrial y la Licencia Fiscal del Impuesto sobre los Rendimientos del Trabajo Personal.

(38) Recargos sobre la Contribución Urbana, la Contribucion Rústica, la Licencia Fiscal del Impuesto Industrial y. la Licencia Fiscal sobre los Rendimientos del Trabajo Personal sufren elevaciones y transformaciones frecuentes. Como significativo, puede verse el Real Decreto-ley 11/1979, de 20 de julio, de medidas urgentes de financiacion de las Haciendas locales. Tambien de. forma mas reciente, un recargo sobre un tributo del Estado. Impuesto sobre la Renta de las Personas Fisicas, y la elevacion del tipo de la Contribucion Territorial Urbana y de la Contribución Territorial Rustica: asi, la Ley $24 / 1983$. de 21 de diciembre. de medidas urgentes de saneamiento y regulación de las Haciendas locales. 
tancias económicas, financieras y tributarias del momento, tanto en relación con el sistema financiero en general como con el particular del Estado, de las Comunidades Autónomas y de los distintos Entes locales. Pero entiéndase bien que esto no quiere decir que se desarrollen medidas especiales o específicas para cada Ente, sino que adoptados unos criterios de generalidad se permitan determinadas alternativas, y cuando no fuesen posibles o convenientes alguna o algunas se suplan con otras de tipo más especial.

Las Comunidades Autónomas pueden, dentro de su margen de competencias, cooperar a la suficiencia de medios de los Entes locales.

Existen algunas cuestiones peculiares a tratar en relación con las Comunidades Autónomas.

La primera cuestión es la de que el artículo 142 de la Constitución prevé la posibilidad de que la suficiencia de medios de los Entes locales se garantice con participación en los tributos de las Comunidades Autónomas y, en su caso, éstas deberían establecer tales participaciones mediante Ley. Será una medida adecuada y oportuna cuando esa suficiencia no se logre a través de los medios de que dispone el Estado. Pero además puede ser interesante para corregir diferencias financieras entre Entes locales cuando éstas no se subsanen por otras vías, tanto por falta de la suficiente operatividad como por imposibilidad de subsanación o desconocimiento de tales insuficiencias.

También pueden establecerse recargos sobre los tributos de las Comunidades Autónomas para suplir deficiencias financieras de los Entes locales (39). Igualmente estos recursos pueden ser una vía adecuada de financiación y de corrección financiera de desigualdades entre Municipios, aunque atenuada porque dependerá de la exacción principal, es decir, del montante del tributo de la Comunidad Autónoma.

Las transferencias de las Comunidades Autónomas a los Entes locales es también una medida financiera permitida, aunque menos fundamental, pero puede resultar muy adecuada para corregir posibles desigualdades o discriminaciones locales.

(39) La posibilidad de establecer recargos en favor de los Entes locales sobre los tributos de las Comunidades Autonomas no esta prohibida. Además, en el Proyecto por el que se aprueban las Bases de la Administracion local, se preve el establecimiento de recargos sobre impuestos propios de las Comunidades Autonomas (art. 109). 
Las Comunidades Autónomas pueden corregir mejor dichas desigualdades o discriminaciones por conocerlas mejor.

Finalmente, hemos de indicar que cuando las Comunidades Autónomas hagan uso de lo que se permite en el artículo 6, 3, de la Ley Orgánica 8/1980, de 22 de septiembre, de Financiación de las Comunidades Autónomas (40), deberán en todo caso garantizar que los recursos de los Entes locales no se vean mermados ni reducidos en sus posibilidades de crecimiento futuro. ¿Cómo deberán hacerlo? La Ley no lo dice, pero podría hacerse mediante un recargo a favor de los Entes locales o mediante una participación en los tributos de las Comunidades Autónomas, también a favor de los Entes locales.

No sería adecuada la vía de las transferencias porque ésta es un ingreso menos fundamental, según lo dispuesto en el artículo 142 de la Constitución, y, además, podría por posible congelación o crecimiento poco adecuado mermar en un futuro los recursos de los Entes locales, lo cual no está legalmente permitido.

En suma, en el artículo 142 de la Constitución existen unos criterios y unos principios que deben ser respetados, si se quiere que la suficiencia o autónomía financieras de las Corporaciones locales se logre plenamente de acuerdo con lo previsto en este precepto, que ocupa la categoría máxima en la jerarquia de las fuentes normativas de nuestro ordenamiento jurídico.

(40) El articulo 6. 3. de la Ley Organica de Financiacion de las Comunidades Autonomas establece lo siguiente: "Las Comunidades Autonomas podran establecer y gestionar tributos sobre las materias que la legislacion de Regimen local reserve a las Corporaciones locales. en los supuestos que dicha legislacion lo prevea y en los terminos que la misma contemple. En todo caso. deberan establecerse las medidas de compensación o coordinación adecuadas en favor de aquellas Corporaciones, de modo que los ingresos de tales Corporaciones no se vean mermados ni reducidos tampoco en sus posibilidades de crecimiento futuro". 


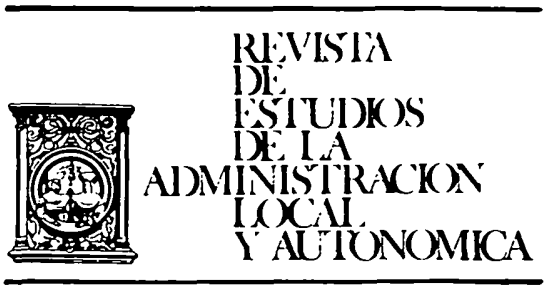

\section{CRONICAS}


REALA-1986, núm. 229. GONZALEZ SANCHEZ, MANUEL. REFLEXIONES SOBRE LA AUTONOMIA O...

REALA-1986, núm. 229. GONZALEZ SANCHEZ, MANUEL. REFLEXIONES SOBRE LA AUTONOMIA O... 